\title{
Engineering and Technology Journal
}

Journal homepage: engtechjournal.org

\section{Studying the Erosion Corrosion Behavior of NiCrAlY Coating Layer Applied on AISI 446 Stainless Steel Using Thermal Spray Technique}

\author{
Ghufran J. Matrood ${ }^{\mathrm{a}}$, Ahmed M. Al-Gaban ${ }^{\mathrm{b}}{ }^{\mathrm{b}}$, Hussain M. Yousif ${ }^{\mathrm{c}}$ \\ ${ }^{a}$ Materials Engineering Department, University of Technology, Baghdad, Iraq, \\ mae.19.41@grad.uotechnology.edu.iq \\ ${ }^{\mathrm{b}}$ Materials Engineering Department, University of Technology, Baghdad, Iraq, \\ a.alghaban@uotechnology.edu.iq \\ ${ }^{\mathrm{c}}$ Ministry of Industry and Minerals, State Company for Steel Industries, Baghdad, Iraq. \\ hussainyousif68@yahoo.com \\ *Corresponding author.
}

Submitted: $23 / 04 / 2020$

Accepted: 10/09/2020

Published: 25/11/2020

\section{K E Y W O R D S}

NiCrAlY coating, molybdenum, erosion corrosion resistance, flame thermal spray.

\section{A B S T R A C T}

Erosion-Corrosion behavior of NiCrAlY coatings deposited on 446 stainless steel samples by flame thermal spraying was performed in this research. The hardness of uncoated and coated sample is measured, using HVS-1000 Digital Micro hardness Tester. The results of hardness show that the coated samples have higher hardness than uncoated samples. Microstructure and phase analysis of the coating layer was observed by using optical microscope, X-ray diffraction (XRD), and SEM respectively. Erosion-Corrosion test was performed in different period of time (6, 12, and $18 \mathrm{hr}$.) using the erosion-corrosion system. The result shows that because of uniform distribution and homogeneous of coating layer, weight loss was very low and approximately equal in all period of testing time.

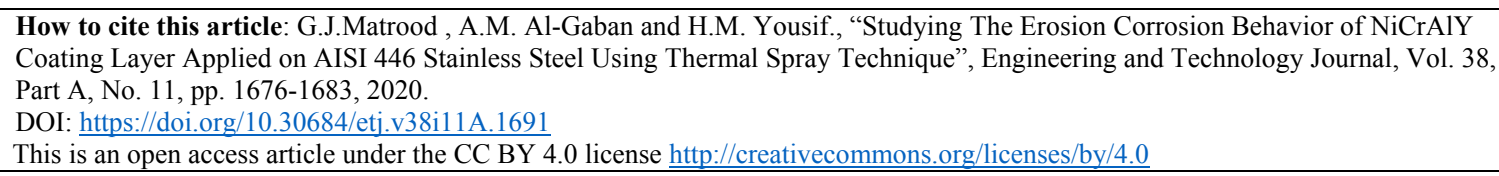

\section{INTRODUCTION}

Erosion-corrosion of metallic materials describes the material degradation process where mechanical wear by solid particles, liquid or the combination of both processes interacts with corrosion caused by dissolution or surface oxidation [1]. 
In high-temperature acidic environments, erosion can increase corrosion by removing the protective passive film and exposing the underlying metal surface to the corrosive medium [1-3] or by creating less protective surface films with embedded particles [4] and increasing the mass transfer coefficient by creating turbulent conditions or by creating a rough surface [5].

The resistance to abrasion, erosion, and corrosion of the components are greatly increasing by depositing a protective coating layer and this is growing industry of developing economic significance $[6,7]$. Nickel based alloys coating is utilized in applications that require resistance to wear combined with hot corrosion or oxidation resistance [8].

MCrAlY (where $\mathrm{M}=\mathrm{Co}$ or Ni ) series are used as a part of TBC (Thermal barrier coating ) coating system as a bond coat bonding aiding layer and protective oxides former or as a final coating layer to protect the super alloy and steels from the harsh and hot environments $[9,10]$.

A coating may be defined as a near surface region, having properties different from the bulk material it is deposited on. Coatings may be applied to the surface of materials in order to protect the surface from the environment that may produce corrosion or other deteriorative reactions and to improve the surface's appearance [11]. There are many techniques available, e.g. electroplating, vapor depositions, thermal spraying etc.

Thermal spraying is a group of coating processes that work on deposited of melt or semi- melt or solid state material on the other material surface. The coating material is spraying in highly acceleration. The coating particles can permanently deform during collision with the surface of the substrate and form the coating layer. Flame thermal spray is considered one of the earliest types of process spraying. The coating material may be used in powder or wires forms. The gases used to produce heat are usually oxygen and acetylene. The flare melt the coating material and rapidly ejected to the substrate surface [12].

The aim of the research is to increase the erosion-corrosion resistance of an AISI 446 stainless steel by depositing a coating layer of NiCrAlY by using flame thermal spraying process.

\section{EXPERIMENTAL PROCEDURE AND MATERIALS USED}

\section{Materials}

The powder used in this research is NiCrAlY with the chemical components shown in Table 1. The particle size of the powder has a range of 25-53 microns.

TABLE I: Chemical composition of the powder

\begin{tabular}{ccccccc}
\hline \hline Element & $\mathrm{Ni}$ & $\mathrm{Fe}$ & $\mathrm{Cr}$ & $\mathrm{Ca}$ & $\mathrm{Si}$ & $\mathrm{Al}$ \\
\hline $\mathrm{Wt} \%$ & 75.5 & 3.95 & 14.94 & 0.05 & 5.33 & 0.2 \\
\hline
\end{tabular}

The sample material used in the current research was (AISI 446) stainless steel. Sample diameter was $22 \mathrm{~mm}$ with thickness $6 \mathrm{~mm}$. Sample pretreatments (degreasing and scale removing) were performed according to standard specifications. The roughening of the samples was carried out using sand shoot blast technique to obtain a rough surface (N12) according to (DIN) standard.

\section{Thermal spraying}

The technique of thermal spraying was used in this research. The automated spraying was used by linking the spray gun to an automated control system that was locally manufactured. The amount of powder entering the spray gun was controlled using an electronic pulse technology system to ensure uniform distribution of the deposited metal on the substrate surface, that was fixed on a table moving with a bi coordinate system (X, Y) as shown in Figure 1 and the flame thermal spraying process are shown in Figure 2. The distance between the spray gun and the sample was $100 \mathrm{~mm}$ [13], and other parameters that related to the thermal spray process are illustrated in Table 2. 


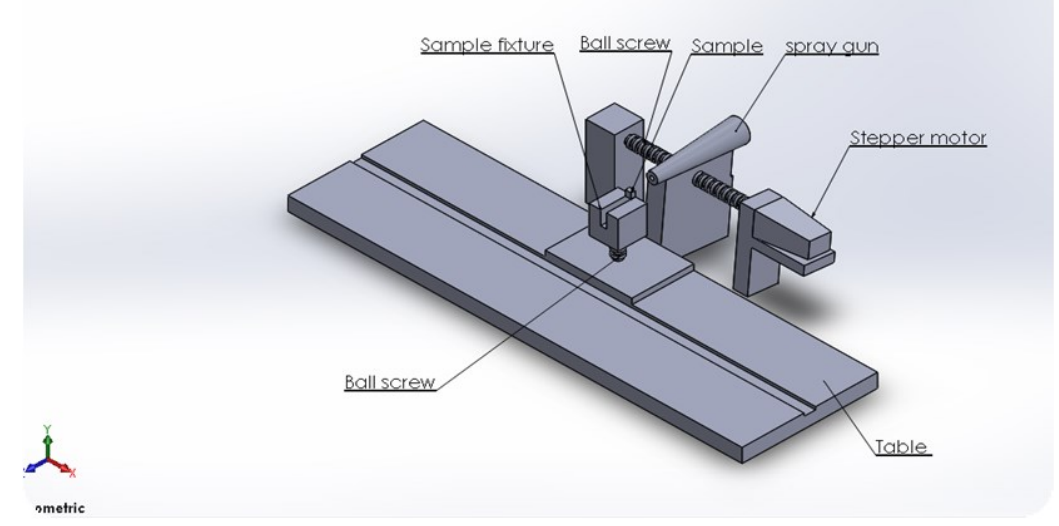

Figure 1: Thermal spray apparatus.

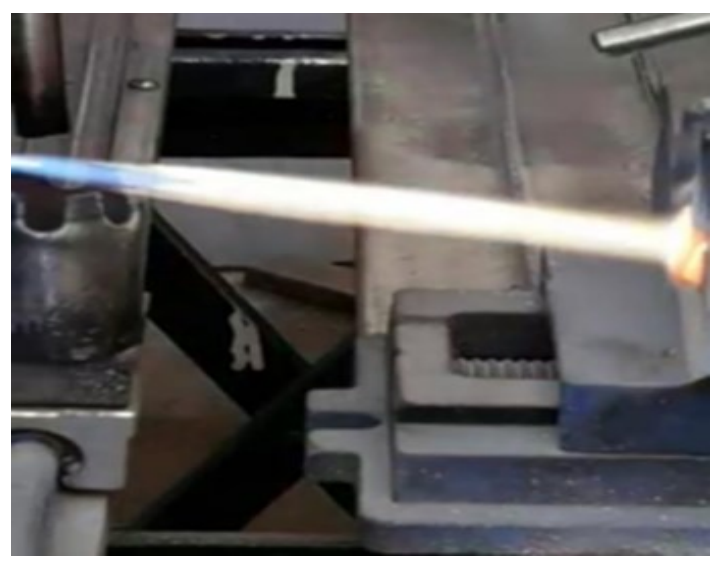

Figure 2: Flame thermal spraying process

TABLE II: Flame thermal spray parameters

\begin{tabular}{ccccccc}
\hline \hline $\begin{array}{c}\text { Oxygen } \\
\text { pressure } \\
(\mathbf{b a r})\end{array}$ & $\begin{array}{c}\text { Acetylene } \\
\text { pressure } \\
(\mathbf{b a r})\end{array}$ & $\begin{array}{c}\text { Powder } \\
\text { feeding } \\
(\mathbf{g} / \mathbf{m i n})\end{array}$ & $\begin{array}{c}\text { Traverse } \\
\text { velocity } \\
(\mathbf{m m} / \mathbf{m i n})\end{array}$ & $\begin{array}{c}\text { Oxygen } \\
\text { pressure } \\
(\mathbf{b a r})\end{array}$ & $\begin{array}{c}\text { Acetylene } \\
\text { pressure } \\
(\mathbf{b a r})\end{array}$ & $\begin{array}{c}\text { Powder } \\
\text { feeding } \\
\mathbf{( g / m i n})\end{array}$ \\
\hline 5 & 0.8 & 10 & 10 & 0.05 & 5.33 & 0.2 \\
\hline
\end{tabular}

\section{TESTS}

\section{Microstructure and phase analysis}

XRD analysis was used to identify the phase composition of the NiCrAlY coating layer by using (Shimadzu company/XRD 6000) at Nano Technology Center/ University of Technology. The microstructure of the coating layer was carried out by optical microscope. The SEM of the coated sample was carried out by (Tescan Vega 3) at the labs of the Ministry of Science.

\section{Microhardness test}

Microhardness test was used to measure the hardness of the coating layer by using microhardness testing device type (HVS-1000 Digital Micro hardness Tester at U.O.T / Materials Engineering Department) as shown in Figure 3. The load used was $(9.8 \mathrm{~N})$ and the holding time was $(15 \mathrm{sec})$. Each sample was examined by taking five readings and the average of the five readings represents the value of the hardness. 


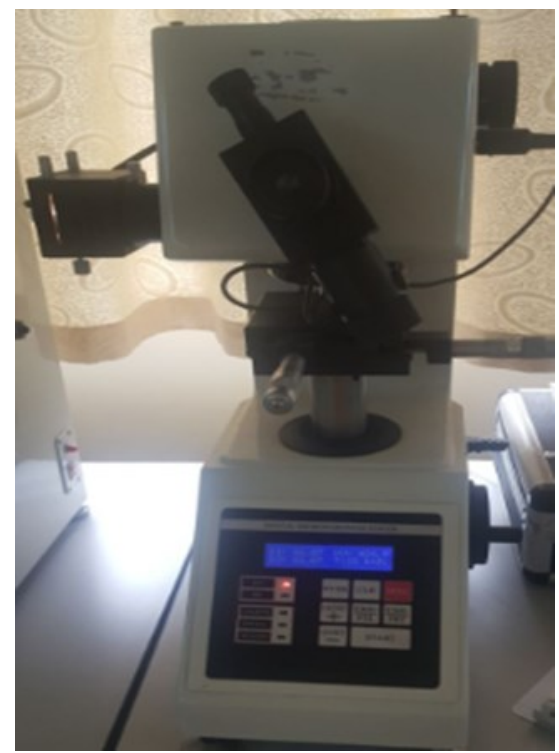

Figure 3: HVS-1000 Digital Micro hardness Tester.

\section{Erosion -Corrosion test}

Erosion-Corrosion test was carried out by using the erosion-corrosion system at Ministry of Industry and Minerals / State Company for Steel Industries, as shown in Figure 4. The system consists of polystyrene tank with two-zones separated by a filter, one of them filled with $(10 \%$ hydrochloric solution) and the other filled with (250) gram glass sand with particle size 50 to 150 micron.

In this test, samples were fixed on the rotary disc, which rotates at $50 \mathrm{r} \mathrm{p} \mathrm{m}$. The acid/sand mixture was directed towards the rotating disc (the samples) using a $1 \mathrm{hp} \mathrm{pump}$, and the mixture flow rate was $40 \mathrm{l} / \mathrm{min}$, which was carried out at intervals of $(6,12$ and 18) hours. Each sample weighed before and after the erosion test, and the difference in weight represents the weight loss.

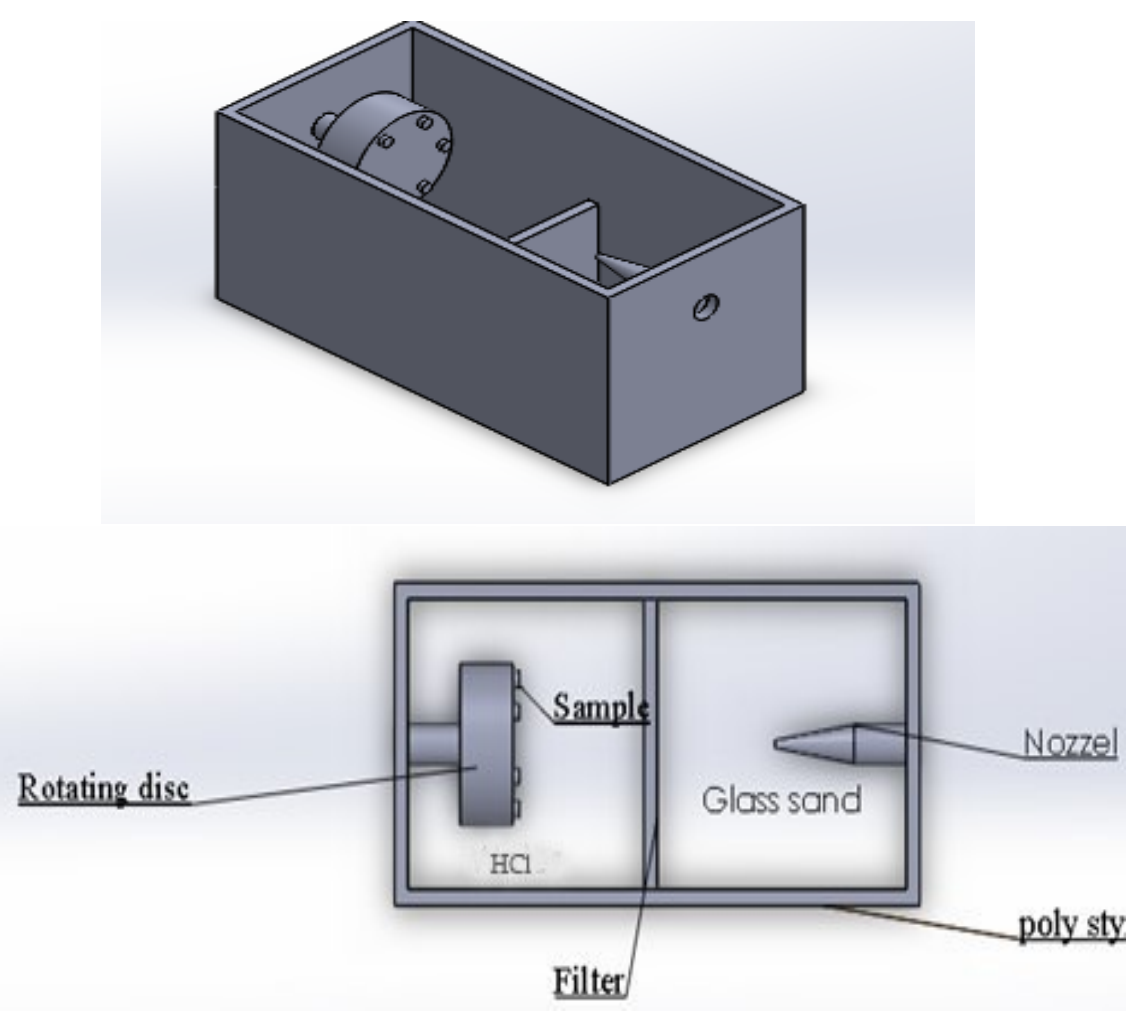




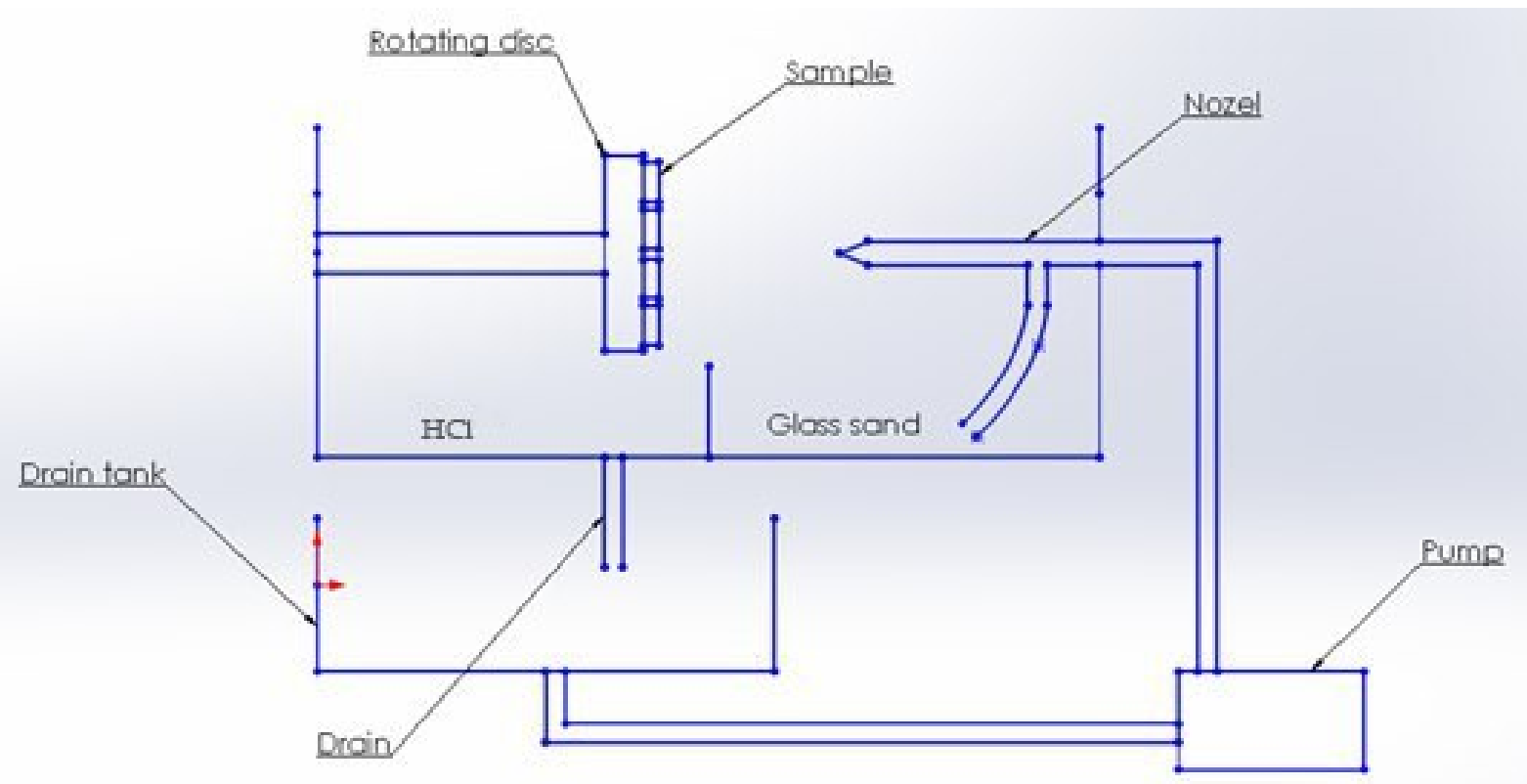

Figure 4: Erosion Corrosion system.

\section{RESUlts AND DiscusSiON}

\section{Microstructure and phase analysis}

The XRD pattern of the coating layer demonstrates three main phases, NiAl, Ni3Al which behave as aluminum reservoir, and finally $\mathrm{A} 12 \mathrm{O} 3$ which is creates from such reservoir, as shown in Figure 5.

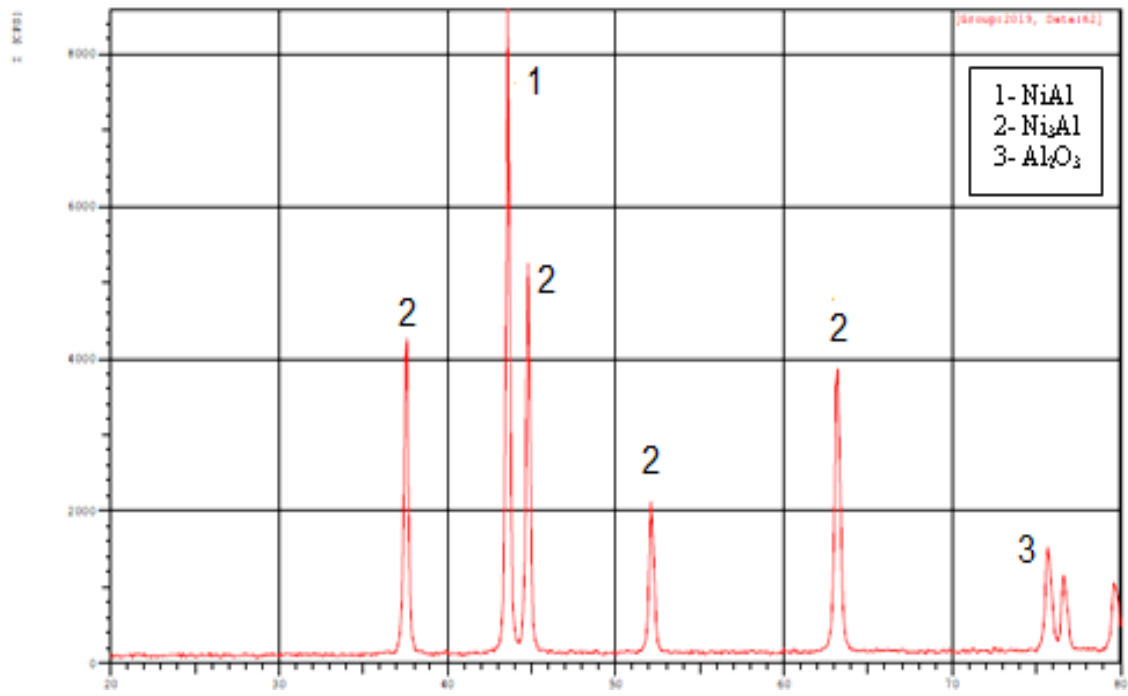

Figure 5: XRD for coating layer.

Figure 6 illustrates the microstructure of the coating layer. It can be shown the uniform distribution of the powder on the surface of the substrate (Figure 6, a). The coating layer- substrate cross section which represented in( Figure 6,b) shows the thin line between coating layer and the substrate, this thin line related to the fusion that creates along the coating layer- substrate inter face. 

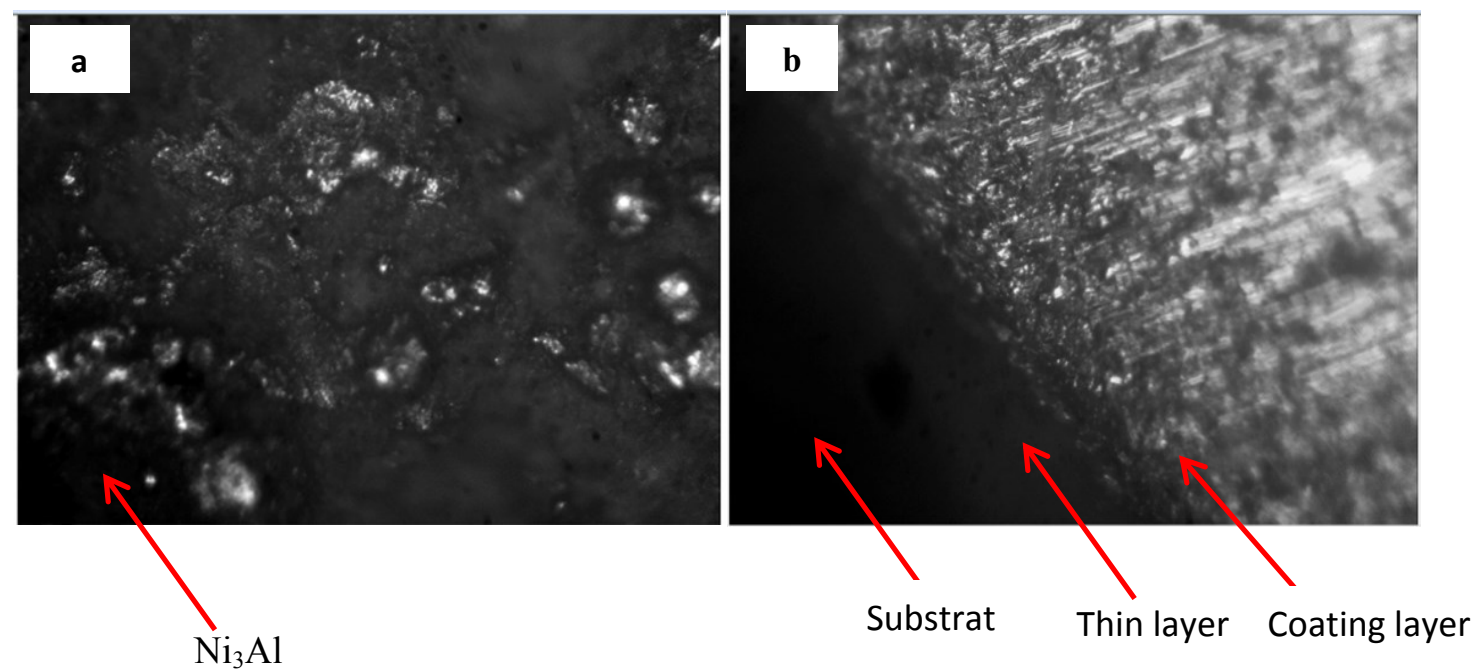

Figure 6: Optical microscope images: (a), Distribution of the powder on the surface of the substrate and (b), The coating layer-substrate cross section

Figure 7 shows scanning electron microscope images of coated sample, from which it shown that the coating layer has homogeneous structure and has little porosity, which make it resistant to erosion-corrosion.

The low amount of pores found in the coatings were promising as high protection against corrosion can be expected from such dense coatings [14].

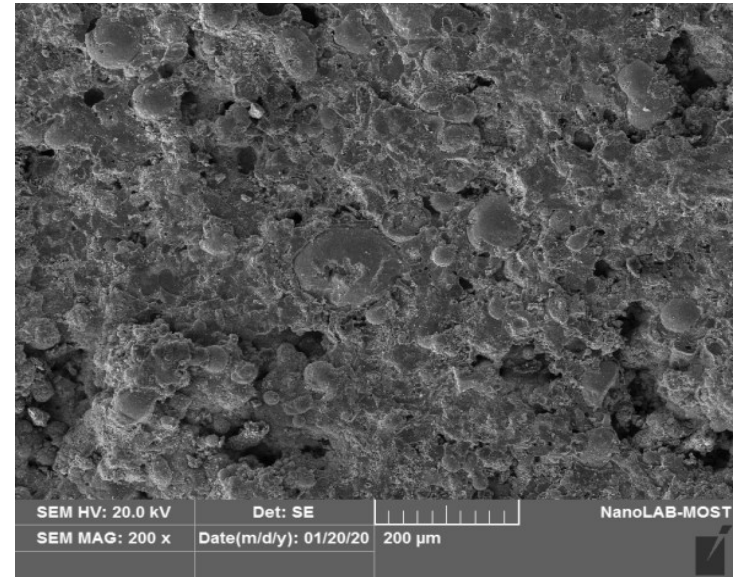

Figure 7: SEM images of coated sample.

\section{Microhardness}

Microhardness test was executed to evaluate the hardness for both coated and uncoated samples. From which it has been shown that the hardness of coated samples was in the range between (600$650 \mathrm{Hv})$, while the hardness of uncoated samples was in the range between $(300-330 \mathrm{Hv})$.

\section{Results of the Erosion-Corrosion Test}

Erosion corrosion test was executed to evaluate the behavior of the coating layer under the impingement of the sand particles and the corrosion due to $10 \%$ hydrochloric solution, in different period of testing time. The relationship between testing time and sample weight loss was studied for the samples have hardness $650 \mathrm{Hv}$, as shown in Figure 8. 


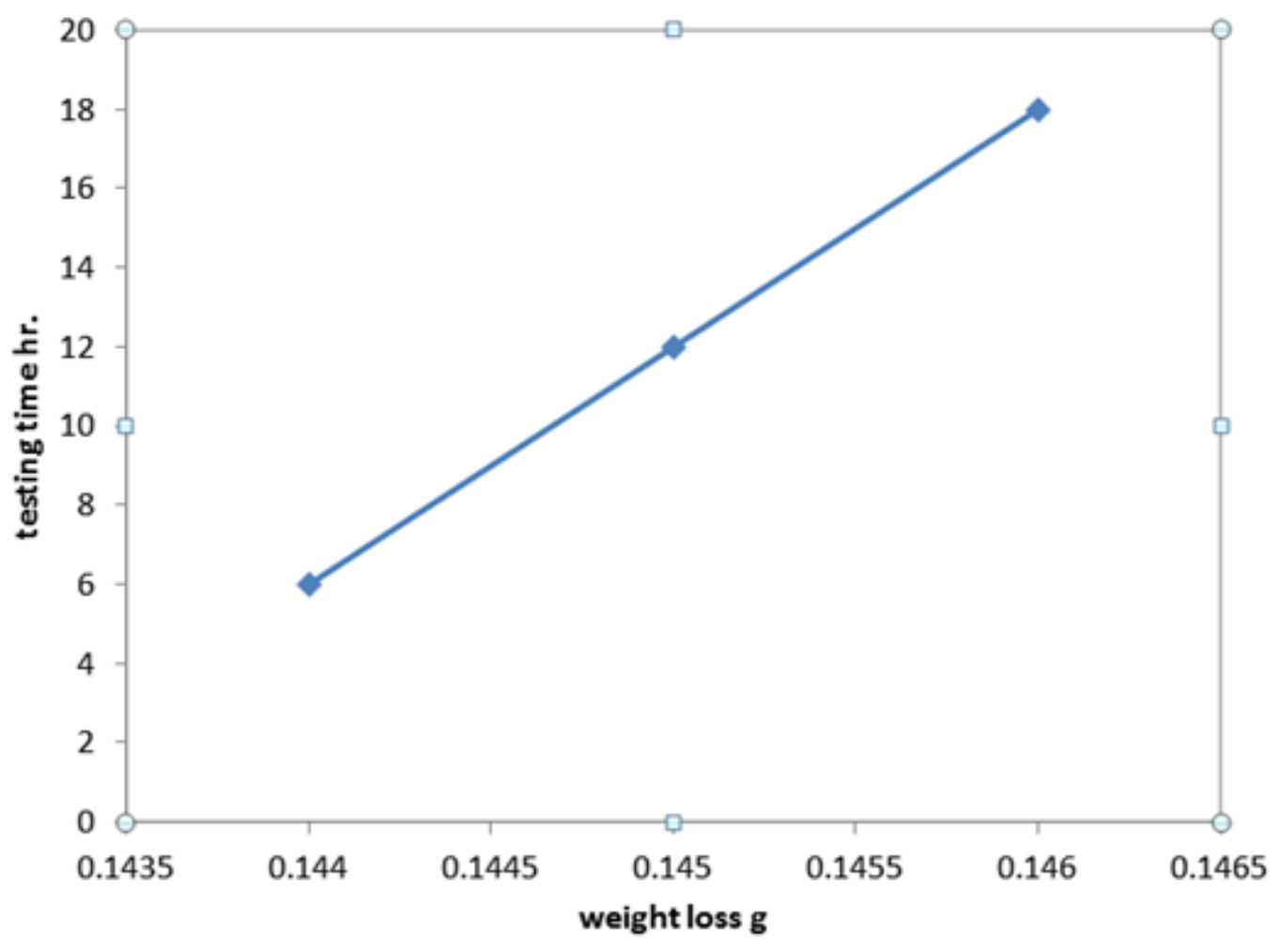

Figure 8: Sample weight loss- testing time relationship

Erosion-Corrosion behavior of all samples at three ranges of time, approximately linear, and weight loss was very low and almost equal in all period of testing time. This may related to the homogeneous and uniform distribution of the coating layer.

\section{Conclusions}

The NiCrAlY coatings were successfully deposited on 446 stainless steel by using flame thermal sprayed process. Microhardness test showed that the hardness of the coated samples was in the range between $(600-650 \mathrm{Hv})$, while the hardness of uncoated samples was in the range between (300-330 $\mathrm{Hv}$ ). The XRD pattern for coating layer revealed NiAl, Ni3Al, and Al2O3 phases which can acts as a protective barrier against the diffusion of species that cause corrosion through the film. SEM analyses informed that the coated sample has homogeneous structure which makes it resistant to erosion-corrosion. From the results of erosion-corrosion test, it observed that the weight loss of coated sample in $10 \% \mathrm{HCl}$ after $6 \mathrm{hr}$. was $0.144 \mathrm{~g}$, while the weight loss after $12 \mathrm{hr}$. was $0.145 \mathrm{~g}$, and after $18 \mathrm{hr}$. The weight loss was $0.146 \mathrm{~g}$. This mean weight loss was very low and approximately equal in all period of testing time.

\section{References}

[1] S. Rajahram, T. Harvey, and R. Wood, "Erosion-corrosion resistance of engineering materials in various test conditions," Wear, Vol. 267, No. 1-4, pp. 244-254, 2009.

[2] R. Wood, "Erosion-corrosion interactions and their effect on marine and offshore materials," Wear, Vol. 261, No. 9, pp. 1012-1023, 2006.

[3] G. Burstein, and K. Sasaki, "Detecting electrochemical transients generated by erosion-corrosion," Electrochemical Acta, Vol. 46, No. 24-25, pp. 3675-3683, 2001.

[4] S. Rajahram, T. Harvey, and RWood, "Evaluation of a semi-empirical model in predicting erosioncorrosion," Wear, Vol. 267, No. 11, pp. 1883-1893, 2009.

[5] K. Sasaki, and G. Burstein, "Erosion-corrosion of stainless steel under impingement by a fluid jet," Corrosion Science,Vol. 49, No. 1, pp. 92-102, 2007. 
[6] S. B. Mishra, K. Chandra, and S. Prakash, "Erosion-corrosion performance of NiCrAlY coating produced by plasma spray process in a coal-fired thermal power plant," Surface and Coatings Technology, Vol. 216, pp. 23-34, 2013.

[7] Takeda, M. Koichilto, S. Takeuchi, K. Sudo, M. Koga, and K. Kazama, "Erosion resistant coating by low pressure plasma spraying," ISIJ international, Vol. 33, No. 9, pp. 976-981, 1993.

[8] M. Rosso, A. Scrivani, D. Ugues, S. Bertini, and H. Materials, "Corrosion resistance and properties of pump pistons coated with hard materials," International Journal of Refractory Metals and Hard Materials, Vol. 19, No. 1, pp. 45-52, 2001.

[9] A. Schnell, C. Bezencon, M. Hoebel, A. S. Khan, M. Konter, and W. Kurz, "Method of growing a MCrAlY-coating and an article coated with the MCrAlY-coating," US Patents 7014923, March 21, 2006.

[10] K. Yuan, "Oxidation and corrosion of new MCrAlX coatings: modelling and experiments," Ph.D. thesis, Linköping University, Sweden, 2014.

[11] G. Antipas, "Spray forming of al alloys: Experiment and theory," Materials Research, Vol.15, No.1, pp. 131-135, 2012

[12] L. Pawlowski,"The science and engineering of thermal spray coatings", John Wiley \& Sons, 2nd edition, England, 2008.

[13] A. S. Fakhri, A. M. Al-Gaban, and H. M. Yousif, "Oxidation behavior of NiAl coatings stainless steel by flame thermal spray", 1st conference on modern electrical, mechanical engineering systems and applications, Baghdad-Iraq 2019.

[14] E.Sadeghimeresht, L. Reddy, T. Hussain, M. Huhtakangas, N. Markocsan, \& S. Joshi, "Influence of KCl and $\mathrm{HCl}$ on high temperature corrosion of HVAF-sprayed NiCrAlY and NiCrMo coatings," Materials \& Design, Vol. 148, pp. 17-29, 2018. 